\title{
PRODUCTION AND CHARACTERISATION OF SRF PREMIUM QUALITY FROM MUNICIPAL AND COMMERCIAL SOLID NON-HAZARDOUS WASTES IN AUSTRIA, CROATIA, SLOVENIA AND SLOVAKIA
}

\author{
Renato Sarc *, Lisa Kandlbauer, Karl Erich Lorber and Roland Pomberger
}

Montanuniversitaet Leoben, Department of Environmental and Energy Process Engineering, Chair of Waste Processing Technology and Waste Management, Franz-Josef-Straße 18, A-8700, Leoben, Austria

Article Info:

Received:

12 July 2019

Revised:

5 September 2019

Accepted:

24 October 2019

Available online:

6 December 2019

Keywords:

Solid recovered fuel (SRF)

Quality assurance

SRF production

Municipal waste

Commercial waste

Cement industry

\begin{abstract}
The production of Solid Recovered Fuel (SRF) and related energy recovery in the European cement industry represents the state of the art in waste management, having evolved into a highly important part of a sustainable and circular economy. This paper describes the production and quality of eight Solid Recovered Fuels (SRF) of PREMIUM quality that are produced from Municipal (Mixed) and selected Commercial Wastes (i.e. Bulky and Lightweight Fraction from Plastic Sorting Plants) in three types of treatment plants located in four European countries, namely Austria, Croatia, Slovenia and Slovakia. The investigated SRF PREMIUM Quality was produced in three different Plant Types applying various process technologies. All three types have been investigated and are described in detail (i.e. flow sheet). Eight SRF PREMIUM Qualities have been comprehensively investigated by sorting, sieving, and physical-chemical analyses. Analyses performed are in accordance with (inter)national standards (i.e. Austrian "ÖNORM", European "EN" standards and CEN TC 343 guidelines). The results gained show that all investigated SRF fulfil the Austrian quality requirements for heavy metals before co-incineration in the cement industry and it can be confirmed that SRF produced in the investigated plants in Austria, Croatia, Slovenia and Slovakia in fact may be declared as "SRF PREMIUM Quality" that can be used for energy recovery on the European SRF market and utilized in the European cement industry.
\end{abstract}

\section{INTRODUCTION}

This introductory chapter covers two issues, namely: "From Municipal and Commercial solid non-hazardous Waste to SRF" and "Applied technologies for production of SRF in investigated countries".

\subsection{From Municipal and Commercial solid non-ha- zardous Waste to SRF}

Waste used in resource management is based on the separate collection of valuable and suitable waste materials (e.g. glass, metals, paper, plastics) for recycling, treatment of biowaste (i.e. composting or fermentation) and highly efficient (co-)incineration of (pre-treated) residual and commercial waste. This statement is confirmed at international level too and is discussed in case studies given by lonescu et al. (2013), Rada et al. (2018), Ranieri et al. (2017), Sipra et al. (2018) and Stępień and Białowiec (2018). Different treatment and manufacturing steps need to be accomplished before a waste becomes a waste fuel for co-incineration plants (e.g. cement industry). Common treatment and manufacturing steps include multistage shredding, classifying, separation of Fe-metals, Non-Femetals, and heavyweight inert materials, as well as sorting out of unwanted materials like polyvinyl chloride (PVC) plastics by using modern near-infrared (NIR)-sorting technology. In total, the waste management industry must pass different development steps, which can be generally divided into four characteristic groups (i.e. legal, material, plant, and economic) to become a fuel supplier for the co-incineration sector. Individual developments and properties of SRF are extensively discussed in Beckmann et al. (2012), Pomberger and Sarc (2012), Sarc and Lorber (2013) and Sarc et al. $(2014,2019)$.

In Austria, the definition of Waste Fuels or Refuse Derived Fuels (RDF) is given in the legally binding Waste Incineration Ordinance (BMLFUW, 2010) as:

"...waste that is used entirely or to a relevant extent for
* Corresponding author:

Renato Sarc

email: renato.sarc@unileoben.ac.at 
the purpose of energy generation and which satisfies the quality criteria laid down in this directive. "

Therefore, after adequate and extensive (pre-)treatment in different processing plants and applying strictly defined quality assurance measures, various non-hazardous and/or hazardous waste materials from households, commerce and industry can be used as RDF in co-incineration plants: e.g.: Sewage Sludge, Waste Wood, High Calorific Fractions from mechanical-physical (MPT) or mechanical-biological treatment (MBT) plants, Calorific Fractions of Household and Commercial Waste, Shredder Light Fractions (e.g. from old vehicles and Waste Electric and Electronic Equipment), Scrap Tyres, Waste Oil and Used Solvents, etc. In the narrow sense of the definition, only solid Waste Fuels which are prepared from non-hazardous sorted or Mixed Solid Wastes (i.e. Municipal Waste Fractions, Commercial Wastes, Production Wastes, Packaging Wastes, Lightweight Fractions from MBT-plants, etc.) including legally defined quality assurance measures and then used for energy recovery are classified as Solid Recovered Fuels - SRF (Lorber et al. 2012). Therefore, SRF is presenting a subgroup of RDF and for both waste fuels the same limit values are defined in the Waste Incineration Ordinance (BMLFUW, 2010).

In regard to the papers from Sarc et al. (2014, 2019), where the requirements for production, quality and quality assurance of solid recovered fuels (SRF) used in Austrian cement industry were presented, this paper expands the scope of investigation, besides on Austrian cement industry, also on Croatian, Slovakian and Slovenian cement plants. Selected information on Mechanical-Biological Waste Treatment (MBT) Plants and co-incineration in cement industry in Croatia have been given in Sarc et al. (2018).

The following investigated SRF that has been used in previously indicated co-incineration plants is extensively investigated, characterised and discussed:

SRF PREMIUM Quality: having particle size distribution $\left(\mathrm{d}_{95}\right) \leq 30$ (up to 35 ) [mm] and lower heating value (LHV) $\geq 18 \leq 25$ [MJ/kg ${ }_{\text {os }}$ (NOTE: OS=original substance) and is used for energy recovery in primary firing system of cement kiln. It is also called main burner fuel (MBF).

According to the latest published data from Eurostat in the year 2017, the following amounts of municipal waste were treated (NOTE: unit in 1,000 t): In total, Austria treated 4,944, Croatia 1,649, Slovenia 773 and Slovakia 2,057. The annual amount of municipal waste per capita [kg/capita] was 562 in Austria, 399 in Croatia, 374 in Slovenia and 378 in Slovakia. The EU 28 average in 2015 was 468 kg/capita, and $479 \mathrm{~kg} /$ capita in 2016 and in 2017. (Eurostat, 2019). A dynamic visualisation of the Municipal Waste management performance by applying RIL-Ternary Diagram Method was published by Pomberger et al. (2017). The RIL-Ternary Diagram method shows the performance of waste management considering the three waste treatment categories (operations): recycling \& composting, incineration and landfilling. The current situation regarding waste management in the four investigated countries is displayed in Figure 1. It is noticeable that in the countries Austria and
Slovenia recycling and incineration (note: in Slovenia since 2015) of waste is targeted, whilst in the other two countries Croatia and Slovakia the focus still is on landfilling of waste. The data shows that a decrease of the landfilling rate in all the mentioned four countries over the last twenty years is visible.

In Table 1 the main input waste materials for SRF production are listed and described by their waste code in accordance with the European List of Waste (Environmental Protection Agency, 2002). The three different production plants described and reported in this paper (Type \#1, Type \#2, Type \#3) are characterised in the following sub-chapter.

\subsection{Applied Technologies for SRF production in in- vestigated countries}

Before a plant operator is ready to opt for co-incineration of SRF, the plant specific technologies applied have to be checked and three fundamental conditions must be fulfilled (Pomberger and Sarc, 2012, Lorber et al., 2012):

- (Inter)national legal compliance, but also legal validity of the operating license,

- A guarantee of supply and of sufficient quantities with the required chemical and physical properties of SRF and

- The quality assurance concept (sampling plan, sampling, and analysing procedure and assessment).

In the following chapter, the three different types of production plants which are relevant for this study and have been investigated are presented with a technical description and an exemplary process flow scheme. For selected SRF production plants, mass balance is given and discussed in Sarc et al. (2018).

\subsubsection{SRF production Plant Type \#1}

This type of plant uses Mixed Municipal and Bulky Waste as its main input material (further details shown in chapter 1). A brief technical description is given below, additionally, the process scheme for an exemplary production Plant Type \#1 is shown in Figure 2.

Main features of this type of plant are:

Waste receivement and storage:

After weighing and documentation checking, trucks with accepted waste material are directed to the receiving pit of MBT plant.

- Pre-processing before biological treatment:

Previous processing involves shredding of the received waste prior to its biological treatment. Waste from the receiving pit is transferred into a shredder, where it is shredded up to $200 \mathrm{~mm}$ and prepared for following biological treatment.

- Biological treatment (bio drying):

The targets of bio drying are: 1) stabilisation and hygienisation of organic matter, 2) water removal, and 3) increasing calorific value of remaining waste. When biological drying is complete after approximately 1 week, the bio dried material is transported to the attached mechanical treatment section in the plant. 
- Pre-procedures/processing before disposal/recovery: In the mechanical section, several devices/machines are used to separate and remove different fractions.
The first step is screening to separate the fine fraction $(<20 \mathrm{~mm})$, which is furthermore treated under anaerobic conditions to produce methane and a fraction that
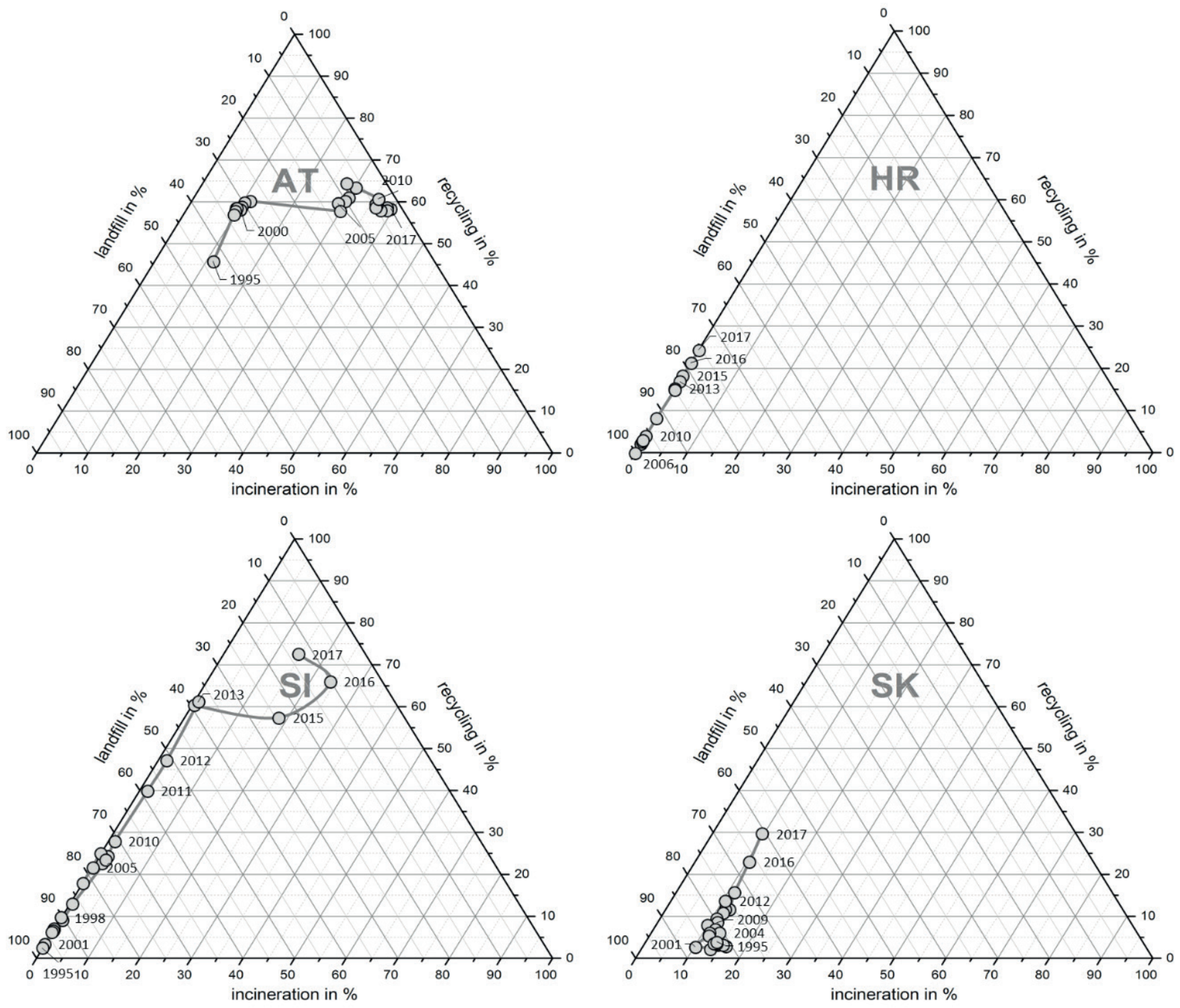

FIGURE 1: RIL-Ternary Diagram Presentation of municipal waste management performance development, data for period 1995-2017 in the investigated countries (updated/modified from Pomberger et al., 2017). AT = Austria, HR= Croatia, SI = Slovenia, SK = Slovakia.

TABLE 1: Main input waste materials for SRF production in each Plant Type described by their waste code in accordance with the European List of Waste.

\begin{tabular}{ll} 
Input & \\
\hline SRF production Plant Type \#1 & SRF production Plant Type \#2 \\
20_03_01: Mixed Municipal Waste & 20_03_01: Commercial Waste \\
20_03_07: Bulky Waste & 20_01_07: Bulky Waste \\
& 15_01_02: Plastics \\
& 15_01_06: Mixed Packaging
\end{tabular}

Various other municipal and industrial waste types used for SRF production:

04_02_09: Wastes from Composite Materials (Impregnated Textile, Elastomer, Plastomer)

07_02_13: Waste Plastic

15_01_01: Paper and Cardboard Packaging

17_09_04: Mixed Construction and Demolition Wastes other than those mentioned in 17_09_01, 17_09_02 and 17_09_03

19_12_12: Other Wastes (including mixtures of materials) from mechanical treatment of wastes other than those mentioned in 19_12_11

20_01_01: Paper and Cardboard

The output/produced SRF legally is not considered as a product but still as a waste and is classified by two waste codes (cf. Sarc et al., 2014):

19_12_10: (quality assured) combustible waste (i.e. SRF)

19_12_12: other wastes from mechanical treatment of wastes (i.e. RDF) 


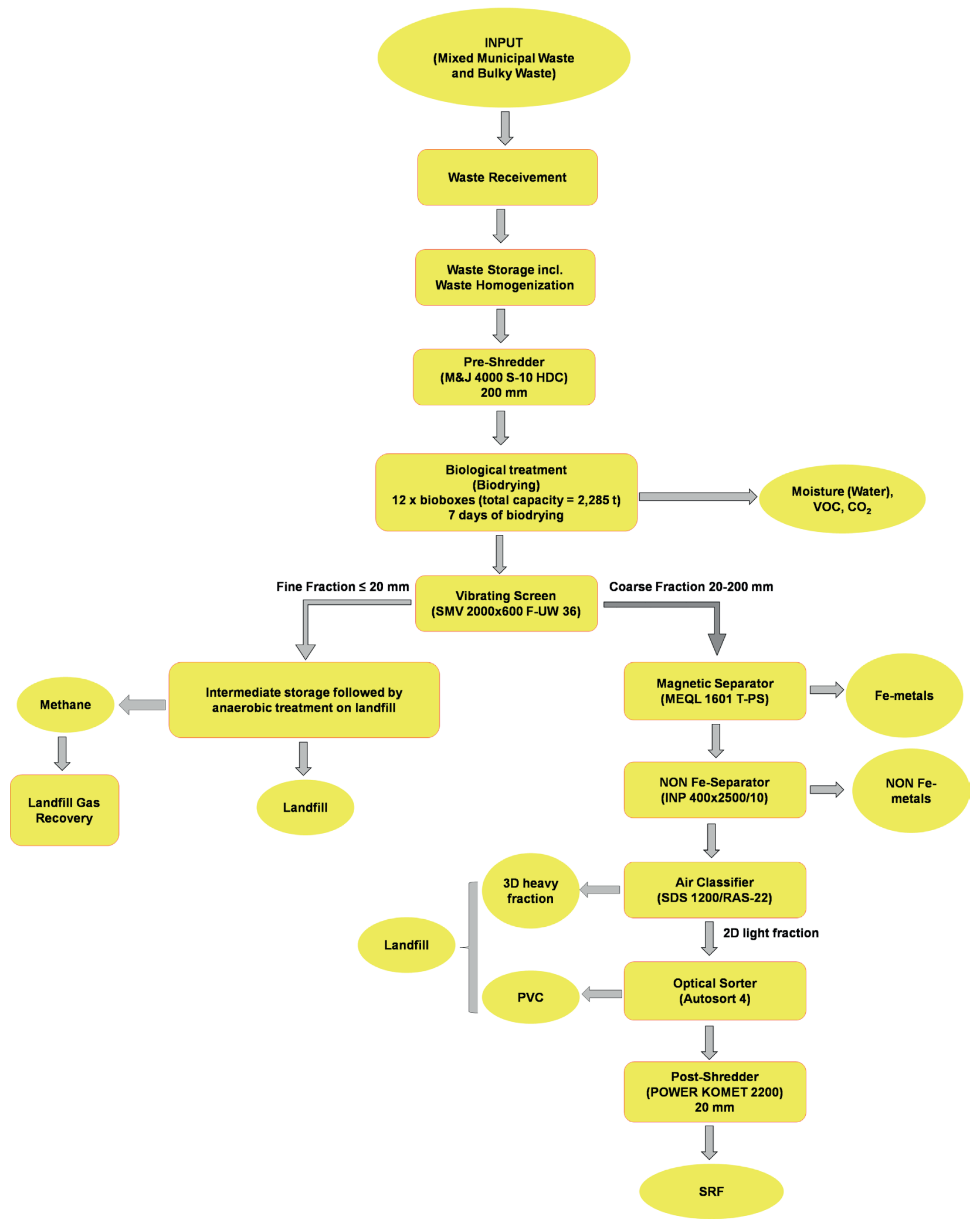

FIGURE 2: Multistage processing scheme as an example of a SRF production Plant Type \#1.

is landfilled. The coarse fraction undergoes Fe- and Non-Fe-separation to remove metals and an air classifier to separate the light (2D) and heavy (3D) fraction. An optical sorting system is installed to sort out PVC plastics and finally followed by a post-shredder (20 $\mathrm{mm})$, to guarantee the required quality of the produced SRF-.

\subsubsection{SRF production Plant Type \#2}

In the production Plant Type \#2, Commercial Waste, 
Bulky Waste and Lightweight Fractions from Plastic Sorting Plants are used to produce SRF (more details see chapter 1). Hereafter, a short technical description is given, and a scheme of an example for production Plant Type \#2 is shown in Figure 3.

Main features of this type of plant are:

- Waste receivement and storage:

After weighing, incoming waste inspection and documents checking, the delivered waste is transported to the mechanical-biological treatment (MBT) plant. There, the waste is unloaded into the waste receiving pits as it is.

- Mechanical pre-treatment:

Pre-treatment of waste includes mechanical treatment of waste, i.e. a whole series of sieving, separation and other processing steps. In this technological process, the waste is separated into two fractions, i.e. a fine $(<200 \mathrm{~mm})$ and a coarse fraction $(>200 \mathrm{~mm})$. The fine fraction undergoes biological treatment, and the coarse fraction is transported to further mechanical treatment. Prior to biological treatment, magnetic materials, such as iron alloys, are separated by using a magnetic separator.

- Biological treatment (bio drying):

After mechanical pre-treatment, the smaller particle size fractions are transferred to a section of the biological treatment plant where they are being processed (i.e. bio dried) for about 1 - 3 weeks, depending on the given input or required output parameters. By aerobic bio drying of Organic Waste Fractions, the waste becomes easier to handle (i.e. lower water content and better processing properties) for the following mechanical treatment.

- Mechanical treatment:

In the mechanical processing area, once again potentially remaining metal portions are removed from the waste in multiple steps and the material stream is shredded to a particle size $<130 \mathrm{~mm}$. The waste is transported to the Non-Fe-separating unit (i.e. Eddy-current separator) and afterwards transferred to a vibrating screen that separates the fine fraction (particle size $<25 \mathrm{~mm}$ ) from the coarse waste. This fine fraction is either sent to a further biological treatment (i.e. stabilisation) or into a waste to energy plant applying fluidized bed combustion technology. For the final steps, an air classifier, an optical sorting system, post-shredder $(30 \mathrm{~mm})$ and magnetic separator are installed to remove the heavy fraction, PVC plastics and metals to ensure the guaranteed quality of SRF.

\subsubsection{SRF production Plant Type \#3}

In type \#3 of the presented SRF production plants, mainly Commercial and Bulky Waste are processed to SRF. A major difference compared to Plant Type \#1 and \#2 is, that this reported plant uses mechanical treatment to process SRF only, whilst the two previous types include a biological treatment (drying) step as well. A technical description of the plant is given below and as an example for this Plant Type a scheme is shown in Figure 4.
The following features of SRF production Plant Type \#3 can be summarized:

- Waste receivement, input storage and pre-sorting:

The storage of input materials takes place in receiving pits, where unwanted materials (unusual bulky parts, which might damage the plant) and recyclable materials (e.g. cardboard, metals, foils, wood etc.) are separated manually and with the help of a mobile machine (i.e. excavator). Additionally, all hazardous waste materials are sorted out.

- Mechanical pre-treatment:

The pre-sorted material gets fed in the pre-shredding unit, which processes the waste to grain sizes $<100$ $200 \mathrm{~mm}$.

- Mechanical treatment:

The shredded material is then conveyed to a ballistic separator, where the material stream gets separated into three fractions. The fine fraction, which is removed by a sieve $(50 \mathrm{~mm})$, undergoes Fe- and Non-Fe-separation before SRF LOW Quality is produced for further waste to energy treatment. The light, 2D-fraction undergoes Fe-separation as well and is further shredded to $30 \mathrm{~mm}$ to guarantee fine grain sizes technically required for SRF PREMIUM Quality. The heavy 3D-fraction is used as SRF MEDIUM Quality after metals (Fe and Non-Fe) are removed.

\section{MATERIALS AND METHODS}

The present chapter describes the recently performed research and development approach as well as the investigation steps carried out regarding the production of premium quality SRF in four European countries (i.e. Austria, Croatia, Slovenia and Slovakia).

A comprehensive investigation was carried out on the characterization of SRF PREMIUM Quality during 4 months (March 2018-July 2018). In total, eight different SRF samples were characterized which all came from different producers (i.e. P1, P2, P3, P4, P5, P6, P6 and P8 respectively). Three of the producers were each from Austria (P1, P5, $\mathrm{P} 8)$ and Croatia (P3, P4, P6) and one producer each from Slovenia (P2) and Slovakia (P7). All the different SRF were extensively investigated by sieving, sorting as well as physical-chemical analyses. Figure 5 shows the different Plant Types for SRF production regarding the different input waste streams. For the benefit of anonymity, the different SRF producers are named as P1-P8 and assigned to one of in total three SRF production Plant Types as seen in the Figure.

For the elaboration of a sampling concept for representative sampling of SRF from the storage depot, particle size $\left(\mathrm{d}_{95}\right.$ in $\left.[\mathrm{mm}]\right)$, bulk density $\left[\mathrm{kg} / \mathrm{m}^{3}\right]$, and other parameters according to ÖNORM 15442 (ASI, 2011a) have been considered. Sampling was then carried out in every SRF production plant which was assigned to one of the three production Plant Types mentioned before (see Figure 5). During sampling procedure (cf. Figure 6), a representative field sample amount between c. 5-22 kg was taken. The samples were dried twice at $40^{\circ} \mathrm{C}$ (required because of $\mathrm{Hg}$ content) and at $105^{\circ} \mathrm{C}$. Then, based on ÖNORM 15415-1 (ASI, 2011b), siev- 


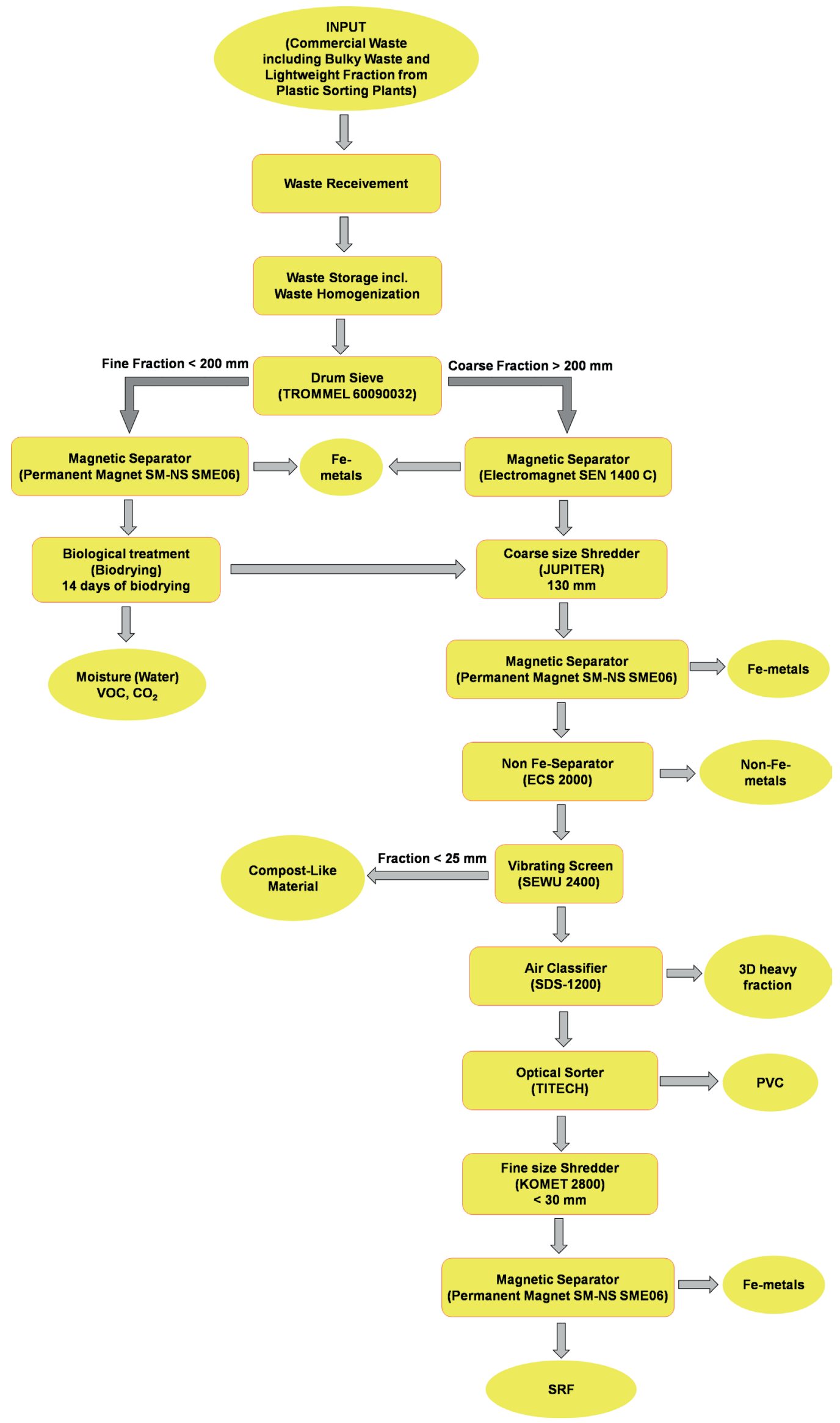

FIGURE 3: Multistage processing scheme as an example of a SRF production Plant Type \#2. 


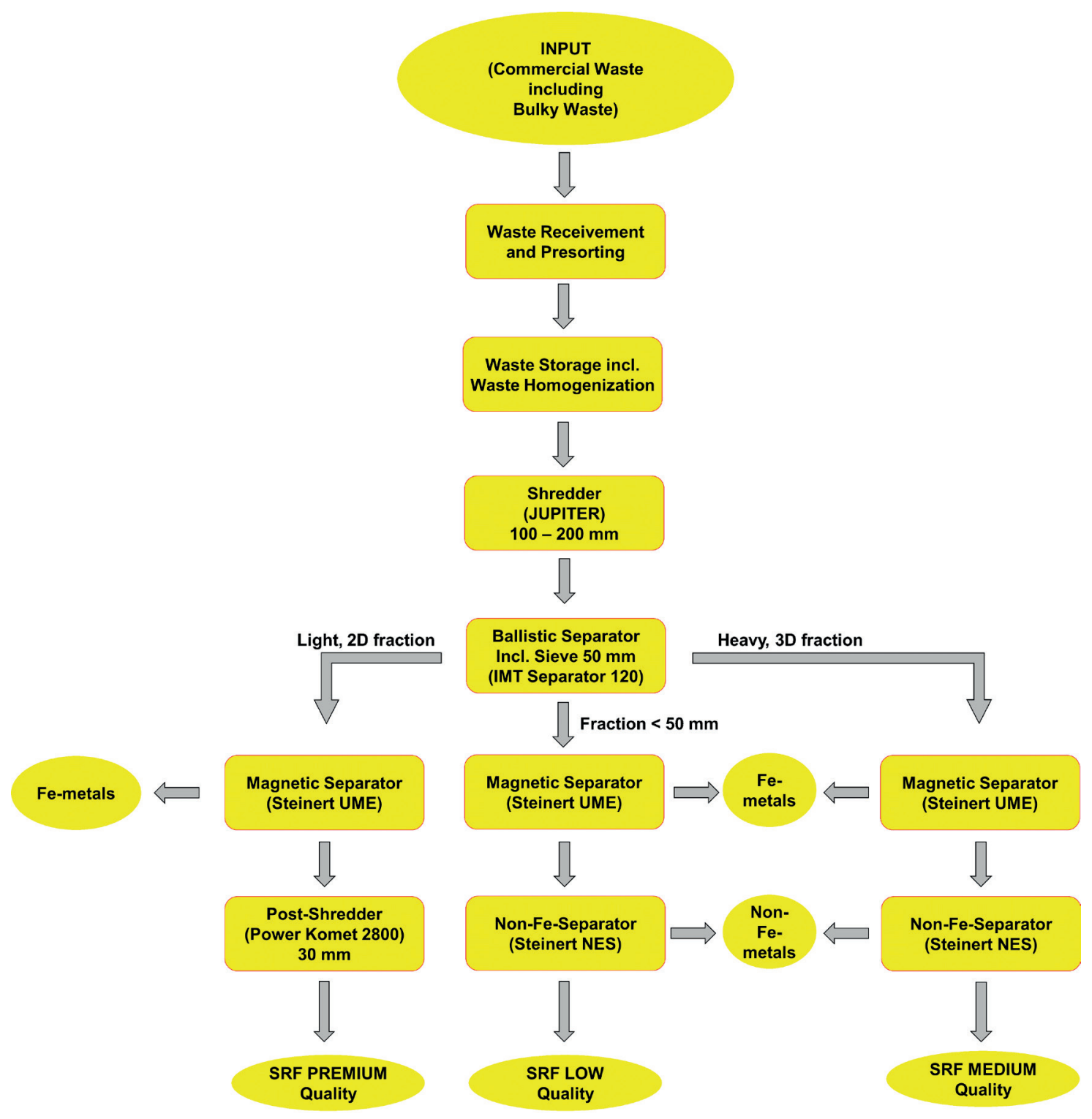

FIGURE 4: Multistage processing scheme as an example of a SRF production Plant Type \#3.

ing analyses were performed on seven SRF. Additionally, sorting analyses of seven investigated samples were carried out and compared to the data published in the Federal Waste Management Plan (FWMP) (BMLFUW, 2011; BMNT, 2017) which represents the mixed municipal waste composition in Austria. Finally, extensive physical-chemical investigations were carried out for all eight SRF samples at the accredited laboratory of the Chair of Waste Processing Technology and Waste Management at the Montanuniversitaet Leoben. All investigations have been performed with dried $\left(40 / 105^{\circ} \mathrm{C}\right)$ materials. Based on the data gained and other relevant data reported in the literature, statistic evaluations and comparisons have been carried out and are presented in the following chapter "Results".

\section{RESULTS AND DISCUSSION}

In Figure 7, the investigated SRF from all three Plant Types are depicted. As already noted in the previous sec- tion, for SRF P6, physical-chemical characterisation was performed only. For all other SRF types (P1-P5, P7-P8) additional to physical- chemical analyses, sieving and sorting analyses have been carried out too.

In the following sub-chapters, the results obtained from sieving, sorting and physical-chemical analyses are presented.

\subsection{Results from sieving analyses}

In total, seven SRF specimen from three different Plant Types have been sampled and analysed. The results achieved are presented in Figure 8.

The results from sieving analyses show that all three different production plants produce materials with comparable grain sizes (see Figure 8). An exception is P4 with a wider particle size distribution, which may be explained by the obvious suboptimal operation of fine shredding machines at the time of SRF sampling. Except for P4, all mate- 

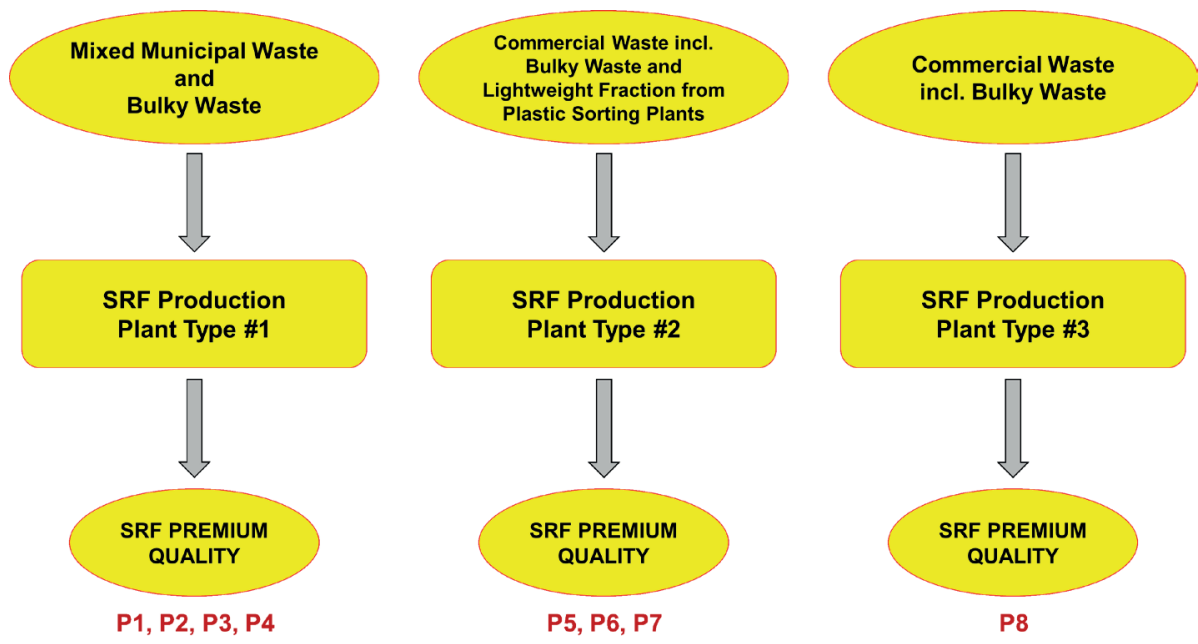

FIGURE 5: Input materials for SRF PREMIUM Quality production in three investigated different production Plant Types (\#1, \#2, \#3) including the allocation of SRF producers (P1-P8).

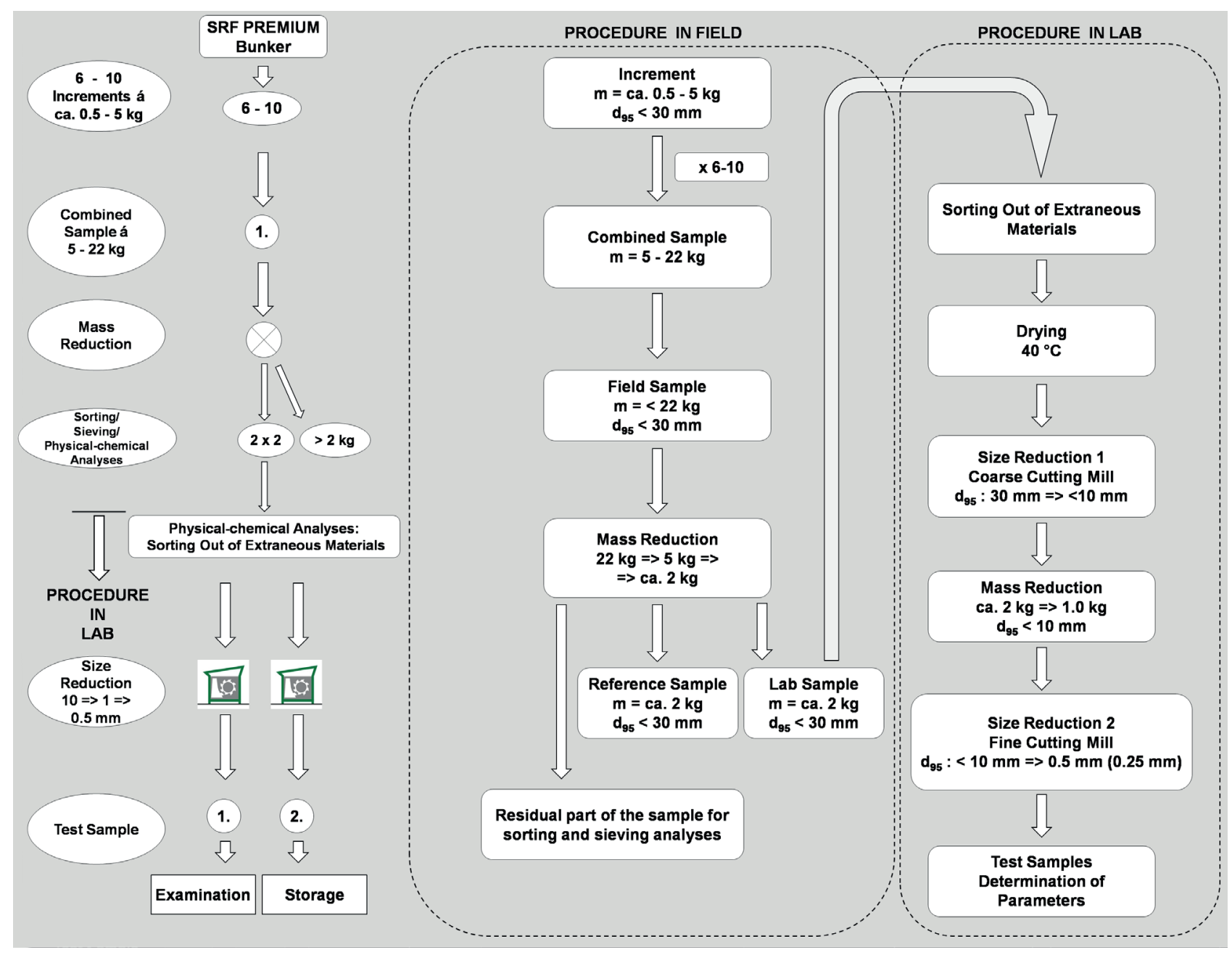

FIGURE 6: Quality assurance concept for external monitoring of SRF characteristics (reproduced from Lorber et al. (2012)).

rials fulfil the technical requirements for particle size (i.e. $d_{95} \leq 30(35) \mathrm{mm}$ ) which is required for the use in primary burners of the cement industry. In the case of P4, $d_{80}$ can reach the required particle size of $30 \mathrm{~mm}$.

\subsection{Results from manual sorting analyses}

In total, seven SRF supplier materials, where each material came from another SRF-production plant, have been analysed. Sorting analyses have been performed based on 

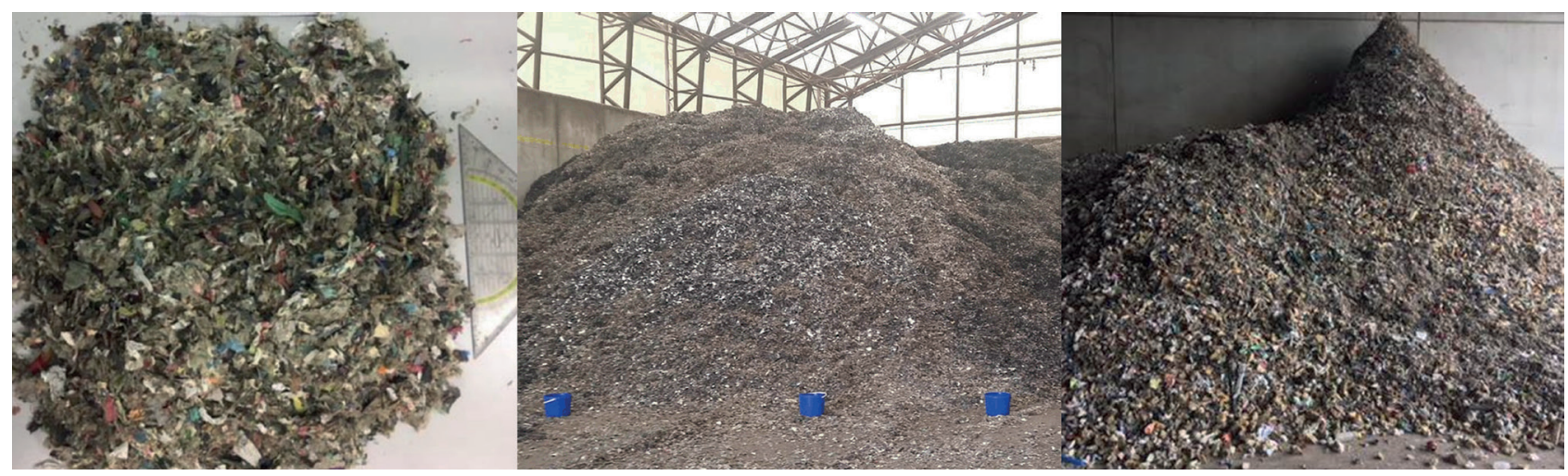

FIGURE 7: Photo documentation of the investigated SRF from Plant Type \#1 (left), Type \#2 (middle) and Type \#3 (right).

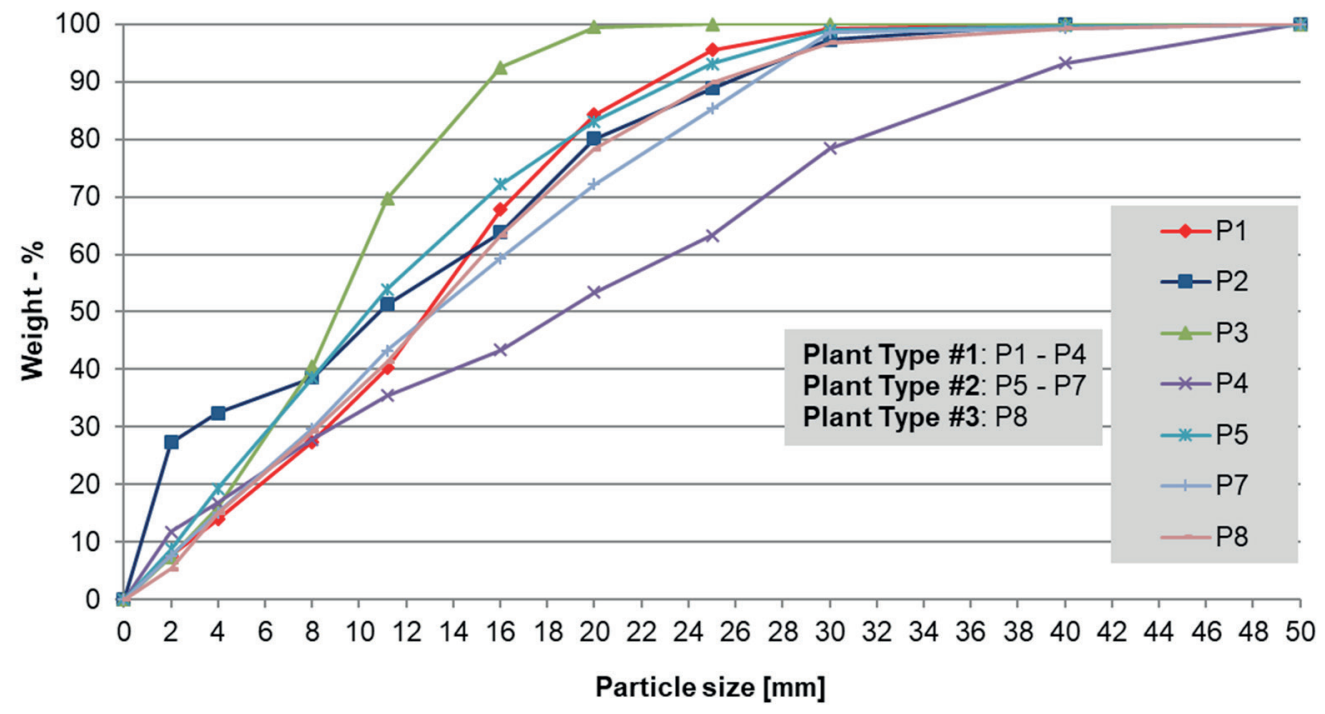

FIGURE 8: Results from sieving analyses of investigated SRF PREMIUM quality.

12 different waste fractions also used in the FWMP 2011 and 2017 (BMLFUW, 2011; BMNT, 2017). The results obtained are given in Table 2.

As shown in Table 2, comparison is done for mean value P1-P4, mean value P5 and P7, value for P8 as well as mean value P1-P8 with data on composition of mixed municipal waste, published for Austria in FMWP (NOTE: data for 2011 and 2017 is shown, as for 2017 there is no data for "fine fraction < $11.2 \mathrm{~mm}$ " available). Analyses results show that proportions of the fractions "Paper, Cardboard and Cardboard Packaging", "Plastics and Lightweight Fraction", "Composite Materials" and "Textiles" are in the same range in all SRF from three Plant Types (i.e. \#1, \#2, \#3) and can be well compared to the data given in FWMP. These fractions are representing about $40 \%$ of the total amount and have a high impact on the heating value (LHV) of the SRF (cf. Table 3).

The second important information regarding SRF PREMIUM Quality is on the observed proportion of "metals, glass and inert materials". Its proportion is in the range of $0.5-1.7 \mathrm{w} \%$ os only, which is much lower than in the mixed municipal waste and a good indicator that the applied technology (especially metal and heavy fraction separa- tion; cf. chapter "Applied Technologies for SRF production in investigated countries") is doing a satisfactory job.

Finally, the proportion of "fine fraction $<11.2 \mathrm{~mm}$ " in SRF PREMIUM Quality shows that in all three Plant Types this amount is in the range: $42.3-71.7 \%$. This result confirms that on one side the applied fine, post-shredding step is efficient and on the other side the reached particle size distribution (including $\mathrm{d}_{50}=$ ca. 11 or $12 \mathrm{~mm}$ ) supports the increase of wanted SRF specific properties, especially calorific value and reaction-technical properties discussed by Beckmann et al. (2012).

\subsection{Results from physical-chemical analyses}

Three groups of results from physical-chemical investigations are presented in Table 3. The energy- and $\mathrm{CO}_{2}$ emission relevant parameters mainly depend on waste input quality and then on technology applied for the processing of SRF. The procedural and mass balance parameters are relevant to the cement kiln and the combustion process (Sarc et al., 2014; 2019). Finally, mass and energy specific heavy metal content (i.e. heavy metal content [mg/ $\mathrm{MJ}_{\mathrm{DM}}$ ] as a product of pollution $\left[\mathrm{mg} / \mathrm{kg}_{\mathrm{DM}}\right.$ ] and lower heating value $\left[\mathrm{MJ} / \mathrm{kg}_{\mathrm{DM}}\right]$ ) are required for fulfilling the Austrian 
TABLE 2: Results from manual sorting analyses of SRF PREMIUM Quality compared with results for mixed municipal waste published in Federal Waste Management Plan 2011 and 2017 (BMLFUW, 2011; 2017).

\begin{tabular}{|c|c|c|c|c|c|c|c|c|c|c|c|c|}
\hline \multirow[b]{2}{*}{ Fractions [w\% $\left.{ }_{0 \mathrm{os}}\right]$} & \multicolumn{5}{|c|}{ Plant Type \#1 } & \multicolumn{3}{|c|}{ Plant Type \#2 } & \multicolumn{2}{|c|}{ Plant Type \#3 } & \multirow{2}{*}{$\begin{array}{l}\text { FWMP } \\
2011\end{array}$} & \multirow{2}{*}{$\begin{array}{l}\text { FWMP } \\
2017\end{array}$} \\
\hline & P1 & P2 & P3 & P4 & $\begin{array}{l}\text { MEAN } \\
\text { P1-P4 }\end{array}$ & P5 & P7 & $\begin{array}{l}\text { MEAN } \\
\text { P5-P7 }\end{array}$ & P8 & $\begin{array}{l}\text { MEAN } \\
\text { P1-P8 }\end{array}$ & & \\
\hline $\begin{array}{l}\text { Organic/Biogenic } \\
\text { Waste }\end{array}$ & 0.0 & 0.0 & 0.0 & 0.0 & 0.0 & 0.0 & 0.0 & 0.0 & 0.0 & 0.0 & 20.5 & 17.8 \\
\hline $\begin{array}{l}\text { Paper, Cardboard and } \\
\text { Cardb. Packaging }\end{array}$ & 9.6 & 5.8 & 6.3 & 25.6 & 11.8 & 8.9 & 8.8 & 8.9 & 8.6 & 10.5 & 12.4 & 14.0 \\
\hline Sanitary Articles & 0.2 & 0.6 & 0.1 & 0.2 & 0.3 & 0.0 & 0.0 & 0.0 & 2.4 & 0.5 & 8.2 & 9.6 \\
\hline $\begin{array}{l}\text { Plastics and Light- } \\
\text { weight Fraction }\end{array}$ & 24.6 & 17.0 & 18.1 & 9.3 & 17.3 & 18.0 & 23.7 & 20.8 & 28.1 & 19.8 & 9.7 & 17.6 \\
\hline Composite Materials & 1.7 & 1.2 & 0.1 & 0.4 & 0.8 & 1.0 & 2.4 & 1.7 & 1.1 & 1.1 & 9.5 & 2.0 \\
\hline Textiles & 15.8 & 6.0 & 3.3 & 15.2 & 10.1 & 3.5 & 16.5 & 10.0 & 4.7 & 9.3 & 5.8 & 7.8 \\
\hline Glass & 0.0 & 0.0 & 0.0 & 0.3 & 0.1 & 0.0 & 0.2 & 0.1 & 0.2 & 0.1 & 4.3 & 4.9 \\
\hline Inert Materials & 0.0 & 0.0 & 0.1 & 0.0 & 0.0 & 1.5 & 0.9 & 1.2 & 0.8 & 0.5 & 3.4 & 5.9 \\
\hline Metals & 0.8 & 0.0 & 0.1 & 0.8 & 0.4 & 0.4 & 0.3 & 0.4 & 0.8 & 0.5 & 2.9 & 4.7 \\
\hline $\begin{array}{l}\text { Hazardous Household } \\
\text { Waste }\end{array}$ & 0.0 & 0.0 & 0.0 & 0.0 & 0.0 & 0.0 & 0.0 & 0.0 & 0.0 & 0.0 & 1.2 & 1.5 \\
\hline $\begin{array}{l}\text { Fine Fraction }<11.2 \\
\mathrm{~mm}\end{array}$ & 42.3 & 52.4 & 71.7 & 45.6 & 53.0 & 58.1 & 46.5 & 52.3 & 43.4 & 51.4 & 19.6 & \\
\hline $\begin{array}{l}\text { Other (unidentified; incl. } \\
\text { Wood for FWMP 2017) }\end{array}$ & 5.0 & 16.9 & 0.3 & 2.7 & 6.2 & 8.5 & 0.7 & 4.6 & 9.9 & 6.3 & 2.5 & 14.3 \\
\hline Sum & 100 & 100 & 100 & 100 & 100 & 100 & 100 & 100 & 100 & 100 & 100 & 100 \\
\hline
\end{tabular}

legal input-material (i.e. prior co-incineration) relevant requirements according to the national Waste Incineration Ordinance - WIO 2002 (NOTE: these legal requirements are not relevant for the Croatian, Slovenian and Slovakian SRF situation, but for the benefit of a better understanding and comparison of the SRF quality, this comparison also is shown in the present contribution, cf. Figure 9). The discussion of the results from physical-chemical analyses, which are shown in Table 3 is divided in the three groups like mentioned before.

\section{Energy- and $\mathrm{CO}_{2}$-emission:}

The Lower Heating Value (LHV) from Plant Type \#1 is significantly lower than from samples collected from Plant Type \#2 and \#3, which can be explained by different input materials. Whilst in Plant Type \#2 and \#3 Commercial Waste, Bulky Waste and Lightweight Fraction are used only, which results in a higher LHV, in Plant Type \#1 Mixed Municipal Waste as input material is also used for SRF production, which leads to a lower LHV because of a reduced amount of the fractions "Plastics and Lightweight Fraction" and "Composite Materials" (see Table 2). Additionally, it is also shown that samples with higher heating values result in higher $\mathrm{CO}_{2}$ emissions, which is also discussed in Sarc et al. $(2014,2019)$. It must be noted, that sample P8 in that case is an exception of this statement, which shows that the actual composition of the input material has a significant impact on SRF quality but the general correlation between Plant Type and SRF specifications is not that pronounced.

\section{Procedural and mass balance:}

The required market values for water and ash content of SRF are generally between 15 and $20 \%$. The physicalchemical analyses show that, except for P5, all investigated samples are in that range. The comparison of the eight
SRF show that even in Plant Types with the same applied technology and same input materials, the specific quality of these input materials has a significant effect on water and ash content in the SRF and a general valid statement for specific Plant Types cannot be declared for this issue. Plant Type \#1 and \#2 include a bio drying step during processing. Especially for samples P1-P4, where Mixed Municipal Waste is used for SRF processing, the importance of the drying process step is noticeable, because the values for dry matter in the finished SRF are in all cases higher than $80 \%$. Samples P1-P4, which are processed from Mixed Municipal Waste show a lower chlorine content than the rest. This can be explained with the lower amount of the fractions "Plastics and Lightweight Fraction" and "Composite Materials" (see Table 2), which usually contain a higher amount of PVC plastics. This statement is based on a correlation between higher Heating Value (LHV) and higher chlorine content. Additionally to the $\mathrm{Cl}$ content, also the $\mathrm{Cl}$ :S -ratio is a crucial parameter for waste fuels, because it influences the corrosion behaviour during combustion (Lorber et al., 2011; Spiegel et al., 2012). The results obtained show significant changes in the $\mathrm{Cl}$ :S-ratio for the different Plant Types. Plant Type \#1 shows a Cl:S-ratio of 1.8, Plant Type \#2 of 2.5 and Plant Type \#3 of 4.8. The chlorine content in the finished SRF is in most cases still below $1 \%_{{ }_{D M}}$ ' that is required by cement industry on international market. The installation of modern NIR-sorting technology for sorting out PVC can be advisable for Type \#3 production plants when the critical limit may be exceeded and Cl:Sratio must be decreased (Kreindl, 2010; Lorber and Sarc, 2012; Pieber et al., 2012).

\section{Legal requirements for heavy metals:}

Figure 9 shows the data given in Table 2, i.e. heavy me- 
TABLE 3: Results from physical-chemical analyses of investigated SRF PREMIUM Quality and limit values for SRF prior utilization in co-incineration plant (type: cement industry) according to the Austrian WIO 2002.

\begin{tabular}{|c|c|c|c|c|c|c|c|c|c|c|c|c|c|c|c|c|}
\hline \multirow[b]{2}{*}{ 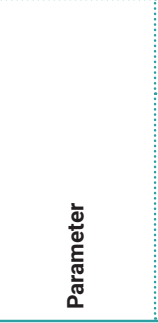 } & \multirow[b]{2}{*}{$\frac{5}{5}$} & \multirow[b]{2}{*}{ 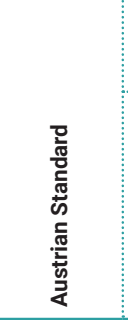 } & \multicolumn{5}{|c|}{ Plant Type \#1 } & \multicolumn{4}{|c|}{ Plant Type \#2 } & \multirow{2}{*}{$\begin{array}{c}\text { Plant } \\
\text { Type } \\
\# 3 \\
\\
\\
\\
\propto\end{array}$} & \multirow{2}{*}{\multicolumn{2}{|c|}{ 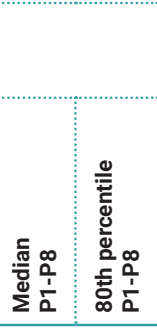 }} & & \\
\hline & & & $\overline{0}$ & 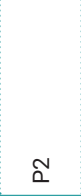 & $\stackrel{m}{0}$ & a & 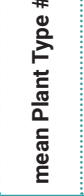 & $\stackrel{20}{\alpha}$ & $\stackrel{\circ}{\circ}$ & $\hat{a}$ & 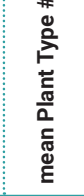 & & & & & \\
\hline \multicolumn{15}{|c|}{ Energy and $\mathrm{CO}_{2}$-emission relevant parameters } & & \\
\hline HHV & {$\left[\mathrm{MJ} \mathrm{kg} \mathrm{DM}^{-1}\right]$} & \multirow{3}{*}{$\begin{array}{c}\text { ASI } \\
(2000)\end{array}$} & 24,9 & 25,1 & 22,4 & 19,9 & 23,1 & 20,2 & 30,6 & 23,0 & 24,6 & 24,8 & 23,9 & 25,1 & & \\
\hline LHV & {$\left[\mathrm{MJ} \mathrm{kg}{ }_{\mathrm{os}}^{-1}\right]$} & & 18,5 & 22,7 & 16,6 & 14,4 & 18,1 & 13,8 & 23,8 & 16,8 & 18,1 & 19,1 & 17,7 & 22,7 & & \\
\hline LHV & {$\left[\mathrm{MJ} \mathrm{kg}_{\mathrm{DM}}{ }^{-1}\right]$} & & 22,9 & 23,1 & 20,6 & 18,3 & 21,2 & 18,6 & 28,1 & 21,2 & 22,6 & 22,8 & 22,0 & 23,1 & & \\
\hline TC & {$\left[\mathrm{w} \%{ }_{\mathrm{DM}}\right]$} & - & 51,6 & 54,1 & 49,6 & 46,6 & 50,5 & 48,7 & 62,9 & 50,5 & 54,0 & 52,9 & 51,1 & 54,1 & & \\
\hline $\mathrm{X}_{\mathrm{B}}^{\mathrm{TC}}$ & {$\left[\mathrm{w} \%_{\mathrm{DM}}\right]$} & \multirow{4}{*}{$\begin{array}{c}\text { ASI } \\
\text { (2011c) }\end{array}$} & 39,6 & 43,2 & 34,7 & 52,4 & 42,5 & 37,3 & 20,7 & 37,0 & 31,7 & 45,0 & 38,5 & 45,0 & & \\
\hline$X_{n B}{ }^{T C}$ & {$\left[\mathrm{w} \%{ }_{\mathrm{DM}}\right]$} & & 60,4 & 56,8 & 65,3 & 47,6 & 57,5 & 62,7 & 79,3 & 63,0 & 68,3 & 55,0 & 61,6 & 65,3 & & \\
\hline $\mathrm{X}_{\mathrm{B}}$ & {$\left[\mathrm{w} \%{ }_{D M}\right]$} & & 47,1 & 50,0 & 38,4 & 55,2 & 47,7 & 36,6 & 25,5 & 32,4 & 31,5 & 40,1 & 39,3 & 50,0 & & \\
\hline$x_{n B}$ & {$\left[\mathrm{w} \%_{\mathrm{DM}}\right]$} & & 40,7 & 37,2 & 35,3 & 22,6 & 34,0 & 38,0 & 63,1 & 45,5 & 48,9 & 43,9 & 39,4 & 45,5 & & \\
\hline $\mathrm{X}_{\mathrm{nB}} \mathrm{W}$ & {$\left[\mathrm{W} \%{ }_{\mathrm{DM}}\right]$} & calculated & 31,2 & 30,7 & 32,4 & 22,2 & 29,1 & 30,5 & 49,9 & 31,8 & 37,4 & 29,1 & 31,0 & 32,4 & & \\
\hline $\mathrm{CO}_{2}$-emission & {$\left[\mathrm{g} / \mathrm{MJ}_{\mathrm{DM}}{ }^{-1}\right]$} & calculated & 49,8 & 48,7 & 57,5 & 44,4 & 50,1 & 60,1 & 65,0 & 54,9 & 60,0 & 46,7 & 52,4 & 60,1 & & \\
\hline \multicolumn{15}{|c|}{ Procedural and mass balance parameters } & & \\
\hline DM & {$[w \%]$} & $\begin{array}{c}\text { ASI } \\
(2006)\end{array}$ & 82,6 & 98,6 & 82,5 & 81,3 & 86,3 & 77,0 & 85,8 & 81,3 & 81,4 & 85,2 & 82,6 & 85,8 & & \\
\hline Ash $\left(815^{\circ} \mathrm{C}\right)$ & {$\left[\mathrm{w} \%{ }_{\mathrm{DM}}\right]$} & $\begin{array}{c}\text { ASI } \\
(1997)\end{array}$ & 11,0 & 10,6 & 19,4 & 18,6 & 14,9 & 23,4 & 11,0 & 19,4 & 17,9 & 12,6 & 15,6 & 19,4 & & \\
\hline $\mathrm{Cl}$ & {$\left[\mathrm{g} \mathrm{kg}_{\mathrm{DM}}{ }^{-1}\right]$} & \multirow{2}{*}{$\begin{array}{c}\text { ASI } \\
(2007) \\
\text { ASI } \\
(2016)\end{array}$} & 5,5 & 6,1 & 4,8 & 4,9 & 5,3 & 11,6 & 7,4 & 8,9 & 9,3 & 14,4 & 6,7 & 11,6 & & \\
\hline S & {$\left[\mathrm{g} \mathrm{kg}_{D M^{-1}}\right]$} & & 3,8 & 2,3 & 2,6 & 3,0 & 2,9 & 6,0 & 1,3 & 3,9 & 3,7 & 3,0 & 3,0 & 3,9 & & \\
\hline \multirow{2}{*}{\multicolumn{8}{|c|}{ Energy specific heavy metal content }} & & & & & & & & \multicolumn{2}{|c|}{$\begin{array}{l}\text { Limit values acc. to } \\
\text { the WIO } 2002\end{array}$} \\
\hline & & & & & & & & & & & & & & & Median & $\begin{array}{c}\text { 80th } \\
\text { percentile }\end{array}$ \\
\hline $\mathrm{Sb}$ & {$\left[\mathrm{mg} \mathrm{MJ}_{\mathrm{DM}}{ }^{-1}\right]$} & \multirow{8}{*}{$\begin{array}{c}\text { ASI } \\
\text { (2011d) }\end{array}$} & 2,5 & 1,1 & 0,9 & 1,1 & 1,4 & 1,4 & 2,0 & 1,9 & 1,8 & 8,7 & 1,7 & 2,5 & 7 & 10 \\
\hline As & {$\left[\mathrm{mg} \mathrm{MJ}_{\mathrm{DM}}{ }^{-1}\right]$} & & 0,1 & 0,1 & 0,1 & 0,1 & 0,1 & 0,2 & 0,1 & 0,2 & 0,2 & 0,1 & 0,1 & 0,2 & 2 & 3 \\
\hline $\mathrm{Pb}$ & {$\left[\mathrm{mg} \mathrm{MJ}_{\mathrm{DM}}{ }^{-1}\right]$} & & 3,6 & 7,4 & 4,4 & 4,1 & 4,9 & 5,3 & 1,7 & 5,3 & 4,1 & 16,5 & 4,9 & 7,4 & 20 & 36 \\
\hline $\mathrm{Cd}$ & {$\left[\mathrm{mg} \mathrm{MJ}_{\mathrm{DM}}{ }^{-1]}\right.$} & & 0,040 & 0,012 & 0,026 & 0,012 & 0,023 & 0,017 & 0,012 & 0,012 & 0,014 & 0,364 & 0,015 & 0,040 & $\begin{array}{c}0.23 \\
(0.45)^{\star}\end{array}$ & $\begin{array}{c}0.46 \\
(0.7)^{\star}\end{array}$ \\
\hline $\mathrm{Cr}$ & {$\left[\mathrm{mg} \mathrm{MJ}_{\mathrm{DM}}{ }^{-1]}\right]$} & & 3,9 & 2,5 & 2,6 & 1,8 & 2,7 & 2,5 & 1,0 & 2,4 & 2,0 & 3,4 & 2,5 & 3,4 & 25 & 37 \\
\hline Co & {$\left[\mathrm{mg} \mathrm{MJ}_{\mathrm{DM}}{ }^{-1}\right]$} & & 0,3 & 0,2 & 0,3 & 0,3 & 0,2 & 0,4 & 0,2 & 0,3 & 0,3 & 0,7 & 0,3 & 0,4 & 1,5 & 2,7 \\
\hline $\mathrm{Ni}$ & {$\left[\mathrm{mg} \mathrm{MJ}_{\mathrm{DM}}{ }^{-1]}\right]$} & & 0,8 & 0,8 & 0,8 & 0,7 & 0,8 & 1,4 & 0,4 & 0,8 & 0,9 & 0,8 & 0,8 & 0,8 & 10 & 18 \\
\hline $\mathrm{Hg}$ & {$\left[\mathrm{mg} \mathrm{MJ}_{\mathrm{DM}}^{-1]}\right.$} & & 0,024 & 0,011 & 0,012 & 0,014 & 0,015 & 0,013 & 0,009 & 0,012 & 0,011 & 0,011 & 0,012 & 0,014 & 0,075 & 0,15 \\
\hline
\end{tabular}

tals investigated according to the international standard and compared (i.e. expressed as exhaustion in \%) to the limit values from Austrian WIO 2002 for SRF used in the cement industry.

From Figure 9, it becomes obvious that the chemical quality (i.e. heavy metals content) of currently used SRF in all the investigated four countries from the Plant Types (i.e. \#1, \#2, \#3) presented in this paper fulfils the Austrian legal limit values for co-incineration in the cement industry and that their quality is in the same range as the SRF utilized on the Austrian market. The notable higher amount of Sb in P8 can be explained with the higher amount of plastic in the input material in Plant Type \#3 (see Table 2), because $\mathrm{Sb}$ is frequently used as a stabiliser in plastics (Sarc et al., 2014).
Also, the values for $\mathrm{Pb}$ and $\mathrm{Cd}$ are significantly higher in $\mathrm{P} 8$. This shows again that the specific input material is a main factor for the resulting quality of SRF and the Plant Type is - as also noted above - only of less importance compared to the input. The reported results on the physical-chemical composition of SRF are representative for the current SRF quality which is available on the waste to energy market for co-incineration plants like cement industry for all the investigated countries.

\section{CONCLUSIONS}

The aim of the present article was to compare the characteristics of different SRF PREMIUM Quality speci- 


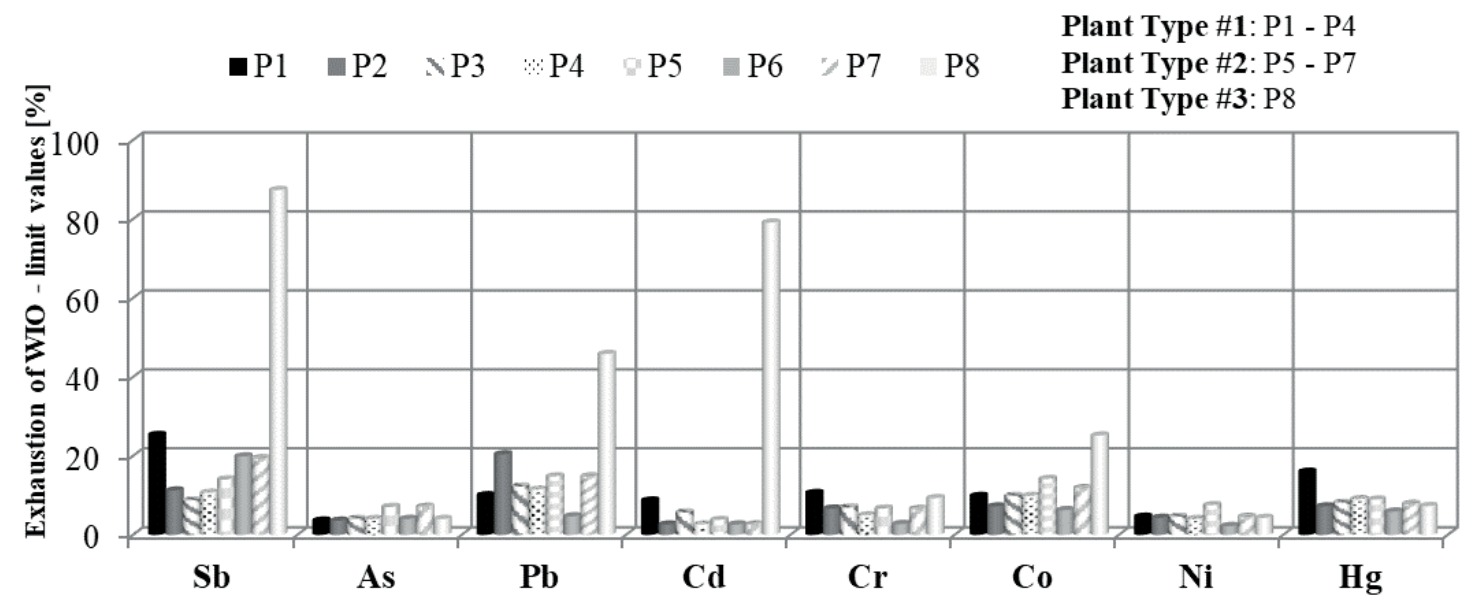

FIGURE 9: Heavy metals analysed in SRF PREMIUM Quality from eight different producers compared to Austrian WIO 2002 (BMLFUW, 2010) 80th percentile limit values that are set 100\% (further interpretation of the comparison is discussed in Sarc et al. (2014)).

men which are usually utilized for energy recovery in the cement industry, including three different types of production plants in Austria, Croatia, Slovenia and Slovakia. The three investigated Plant Types (i.e. \#1, \#2, \#3) differ in the applied processing technology (mechanical, mechanicalbiological) as well as the input materials (Mixed Municipal Waste, Commercial Waste, Bulky Waste, Lightweight Fraction from Plastic Sorting Plants). To characterise the SRF, extensive sorting and sieving analyses, as well as physical-chemical analyses, were all performed in accordance with (inter)national standards (ÖNORM and EN). The results show, that all the investigated SRF meet the quality requirements for Austrian SRF before co-incineration in the cement industry and are comparable with SRF reported in Sarc et al. (2014, 2019). By considering Austrian limit values for heavy metals in SRF utilised in co-incineration plants, the exhaustion of limit values by heavy metal contents of SRF from investigated countries for all three Plant Types is within the range. Regarding the final SRF quality, the different production Plant Types show a trend in produced qualities, but also exceptions appear, which are discussed in the chapter "Results and Discussion". As stated before, it can be confirmed, that type and origin of the input waste used has more influence on the final product quality of SRF than the specific process applied for SRF production. Additionally, multi-stage processing including shredding, classifying, separation of Fe-metals, Non-Femetals and heavyweight inert materials, as well as sorting out of unwanted materials like polyvinyl chloride (PVC) plastics by using modern near-infrared-sorting technology is especially required for production of quality assured SRF. Finally, it can be confirmed and stated that SRF produced in all the investigated eight plants in Croatia, Slovenia and Slovakia are in fact SRF PREMIUM QUALITY that can be traded on the European SRF market and utilized in the European cement industry.

\section{CONFLICT OF INTEREST}

The authors declare no conflict of interest.

\section{ACKNOWLED GEMENTS}

The authors are very grateful to the SRF producers in Austria, Croatia, Slovenia and Slovakia which were collaborating within this study, and to the cement industry in the investigated countries for enabling our investigations on SRF PREMIUM Quality and supporting us with information about waste treatment plants and technology applied as well as market relevant data. Many thanks also to our colleagues and co-workers of the Chair's laboratory, who were responsible for the analytical investigations.

\section{FUNDING}

Partial funding for this work was provided by:

The Center of Competence for Recycling and Recovery of Waste 4.0 (acronym ReWaste4.0) (contract number 860 884) under the scope of the COMET - Competence Centers for Excellent Technologies - financially supported by BMVIT, BMWFW and the federal state of Styria, managed by the FFG.

\section{REFERENCES}

ASI (Austrian Standards Institute), 1997. DIN 51719-Testing of solid fuels - Solid mineral fuels - Determination of ash content, Vienna: ASI.

ASI (Austrian Standards Institute), 2000. DIN 51900-1-Testing of solid and liquid fuels - Determination of gross calorific value by the bomb calorimeter and calculation of net calorific value - Part 1: Principles, apparatus, methods, Vienna: ASI.

ASI (Austrian Standards Institute) ,2006. ÖNORM CEN/TS 15414-1-Solid recovered fuels - determination of moisture content using the oven dry method. Part 1: determination of total moisture by a reference method, Vienna: ASI.

ASI (Austrian Standards Institute), 2007. DIN EN ISO 10304-1-Water quality - Determination of dissolved anions by liquid chromatography of ions - Part 1: Determination of bromide, chloride, fluoride, nitrate, nitrite, phosphate and sulfate, Vienna: ASI.

ASI (Austrian Standards Institute), 2010. ÖNORM EN 15413-Solid Recovered Fuels-Methods for the preparation of the test sample from the laboratory sample. Vienna, Austria: ASI.

ASI (Austrian Standards Institute), 2011a. ÖNORM EN 15442-Solid Recovered Fuels-Methods for sampling. Vienna, Austria: ASI.

ASI (Austrian Standards Institute), 2011b. ÖNORM EN 15415-1-Solid Recovered Fuels-Determination of particle size distribution-Part 1: Screen method for small dimension particles. Vienna, Austria: ASI. 
ASI (Austrian Standards Institute), 2011c. ÖNORM EN 15440-Solid recovered fuels - methods for the determination of biomass content, Vienna: ASI.

ASI (Austrian Standards Institute), 2011d. ÖNORM EN 15411-Solid recovered fuels - methods for the determination of the content of trace elements (As, Ba, Be, Cd, Co, Cr, Cu, Hg, Mo, Mn, Ni, Pb, Se, Tl, $\mathrm{V}$ and $\mathrm{Zn}$ ), Vienna: ASI.

ASI (Austrian Standards Institute), 2016. ÖNORM EN 14582-Characterization of waste - Halogen and sulfur content - Oxygen combustion in closed systems and determination methods, Vienna: ASI.

Beckmann M., Pohl M., Bernhardt D. and Gebauer K., 2012. Criteria for solid recovered fuels as a substitute for fossil fuels-a review. In: Waste Management \& Research 30 (4).

BMLFUW (Bundesministerium für Land- und Forstwirtschaft, Umwelt und Wasserwirtschaft), 2010. Verordnung über die Verbrennung von Abfällen Abfallverbrennungsverordnung - AVV [Waste Incineration Ordinance]. Vienna, Austria: BMLFUW.

BMLFUW (Bundesministerium für Land- und Forstwirtschaft, Umwelt und Wasserwirtschaft), 2011. Federal Waste Management Plan 2011, Vienna, Austria.

BMNT (Bundesministerium für Nachhaltigkeit und Tourismus), 2017. Bundesabfallwirtschaftsplan 2017, ISBN.: 978-3-903129-32-0, Wien.

Environmental Protection Agency, 2002. European waste catalogue and hazardous waste list. Ireland: EPA.

Eurostat on: http://ec.europa.eu/eurostat/web/products-datasets/-/ env_wasmun. Accessed 12 March 2019.

Ionescu G., Rada E.C., Ragazzi M., Mărculescu C., Badea A., Apostol T., 2013. Integrated municipal solid waste scenario model using advanced pretreatment and waste to energy processes. In: Energy Conversion and Management 76, 1083-1092.

Kreindl G., 2010. Herausforderungen der NIR-Sortierung von gemischten Abfällen aus Industrie und Gewerbe [Challenging NIRSorting of Mixed Industrial Waste]. In: Proceedings of the 10th DepoTech Conference (eds KE Lorber et al.), Montanuniversitaet Leoben, Austria, ISBN: 978-3-200-02018-4. Leoben, Austria.

Lorber K.E., Sarc R., Pomberger R., 2011. Herstellung und Einsatz von Ersatzbrennstoffen (EBS) in Österreich (Production and Application of Refuse Derived Fuels in Austria). In: Waste-to-Resources 2011, 4. Internationale Tagung MBA und Sortieranlagen KühleWeidemeier (Ed.), Cuvillier Verlag Göttingen, Germany.

Lorber K.E. and Sarc R., 2012. Waste to energy by preparation of quality controlled solid recovered fuels (SRF). In: Nelles M., Wu K., Cai J., Cheng J.J., et al., eds, Proceedings of $4^{\text {th }}$ ICET Conference. Hefei, China pp. 13-18.

Lorber K.E., Sarc R. and Aldrian A., 2012. Design and quality assurance for solid recovered fuel. In: Waste Management \& Research 30 (4).
Pieber S., Ragossnig A., Pomberger R., et al., 2012. Biogenic carbon-enriched and pollutant depleted SRF from commercial and pretreated heterogeneous waste generated by NIR sensor-based sorting. Waste Management and Research 30, 381-391.

Pomberger R. and Sarc R., 2012. The future of solid recovered fuels (SRF). In: Eumicon, European Mineral Resources Conference 2012 Montanuniversitaet Leoben, Austria. Leoben, Austria.

Pomberger R., Sarc R. and Lorber K.E, 2017. Dynamic visualisation of municipal waste management performance in the EU using Ternary Diagram method. In: Waste Management 61, 558-571.

Rada E.C., Zatelli C., Cioca L.I., Torretta V., 2018. Selective collection quality index for municipal solid waste management. In: Sustainability 10 (1), 257.

Ranieri E., Ionescu G., Fedele A., Palmieri E., Ranieri A.C., Campanaro V., 2017. Sampling, characterisation and processing of solid recovered fuel production from municipal solid waste: An Italian plant case study. In: Waste Management \& Research 35 (8), 890-898.

Sarc R. and Lorber K.E., 2013. Production, quality and quality assurance of Refuse Derived Fuels (RDFs). In: Waste Management 33, 1825-1834.

Sarc R., Lorber K.E., Pomberger R., Rogetzer M., Sipple E.M., 2014. Design, Quality and Quality Assurance of Solid Recovered Fuels (SRF) for the Substitution of Fossil Feedstock in the Cement Industry. In: Waste Management \& Research 32 (7)

Sarc R., Perovic K., Relic I., Lorber K.E., 2018. Mechanical-Biological Waste Treatment Plants in Croatia. In: Thiel S., Thomé-Kozmiensky E., Winter F., Juchelková D. (Eds.): Waste Management, Volume 8, Waste-to-Energy. ISBN: 978-3-944310-42-8. Thomé-Kozmiensky Verlag GmbH, Neuruppin 2018, Germany.

Sarc R., Seidler I.M., Kandlbauer L., Lorber K.E.,Pomberger R, 2019. Design, Quality and Quality Assurance of Solid Recovered Fuels (SRF) for the Substitution of Fossil Feedstock in the Cement Industry Update 2019. In: Waste Management \& Research 37 (9), 885-897.

Sipra A.T., Gao N., Sarwar H., 2018. Municipal solid waste (MSW) pyrolysis for bio-fuel production: A review of effects of MSW components and catalysts. In: Fuel Processing Technology 175, 131-147.

Spiegel W., Magel G. Müller W., 2012. Einfluss von Calciumspezies auf Korrosion und Verschmutzung in MVA und EBS-Kraftwerken (Impact of Calcium Phases on Corrosion and Fouling in Waste-toEnergy Plants). In: Lorber K.E. et al. (Eds.), Proceedings of the $11^{\text {th }}$ DepoTech Conference, Leoben, Austria.

Stępień P., Białowiec A., 2018. Kinetic parameters of torrefaction process of alternative fuel produced from municipal solid waste and characteristic of carbonized refuse derived fuel. In: Detritus 3, 7583 